\title{
TraceCases: A Simulator for RUP Use-Case Analysis
}

\author{
Pallavi Pandit \\ Medi-Caps Institute of Technology and \\ Management \\ A.B. Road, Pigdamber \\ Rau, Indore
}

\author{
Meena Sharma \\ Institute of Engineering and Technology \\ Khandwa Road \\ Indore, MP
}

\begin{abstract}
Learning styles of different learners vary. So, different approaches to explaining theoretical concepts should be followed. TraceCases is a simplified tool for understanding RUP Use-Case Analysis. A use-case model is given as input, validated and analysis classes are derived and shown. Metrics for use-case model and analysis classes are computed. Traceability between use-case model and analysis classes is illustrated.
\end{abstract}

\section{General Terms}

I.6.4 [Simulation and Modeling]: Model Validation and Analysis - Experimentation

\section{Keywords}

Pedagogy, use cases, analysis classes, VOPC class diagram, traceability, metrics.

\section{INTRODUCTION}

Different learning patterns of students were observed while taking a survey of a Software Design course[1]. Each student exhibited a different capability to learn based on the personality types of students.

In their paper, Thomas, Ratcliffe, Woodbury, and Jarman (2002) closely observed the learning styles of 107 introductory computer science students and concluded that there were slightly more active than reflective learners, a vast majority of visual learners over verbal, and almost equal in number of sensing or intuitive and sequential or global learners.[1]

Many empirical studies have explored the relationship between the Myers-Briggs Type Indicator (and its numerous associated factor types-Extraversion, Sensing, Thinking, Judging, Introversion, Intuition, Feeling and Perceiving) and software engineering.[1]

The traditional methods of teaching do not take the above factors into account and focus mainly on the textual aspect of learning. The aforementioned studies draw our attention to the fact that the blackboard style of teaching does not suffice to exploit the learning patterns of each and every kind of student. Some students find it difficult to engage themselves totally with the chalk-and-talk learning paradigm. The recommended different types of learning methodologies which can enhance the grasping power of students may include case studies, hands-on activities and other simulating approaches.

TraceCases employs a simplified approach for demonstrating RUP concepts to students. Its purpose is giving them an introductory hands-on on the analysis and design discipline, mainly focusing on the use case analysis activity.

\section{LITERATURE SURVEY}

The authors in [2] have introduced a new strategy for teaching RUP and UML in Software Engineering Courses to decrease the learning time and increase the skills of the students. They have incorporated the software engineering process workflow with RUP and UML. New innovations using multimedia resources and support tools were used to explain RUP and UML to the students. The authors have prepared flash tutorials to demonstrate the "how-to's", to cover specific knowledge and to reduce practice gaps (How to create an RUP project, how to pass from the Business model to the Requirements Model, etc.). Their learning model makes some changes in RUP workflows and models to suit the better needs of students. As a result of their new strategy, learning period in the first four phases of RUP has been dramatically reduced.

Jan Bergandy in [3] takes on a new approach to teaching RUP wherein the course contents have the RUP process framework integrated with the Software Engineering course curriculum. The students are required to develop a medium sized project for a real customer. RUP was chosen as the process framework both for the project and served as a structure for organizing the contents of the software engineering course.

\section{RUP USE CASE ANALYSIS}

Rational Unified Process is the result of adopting the best practices of all the different methodologies. It has unified different aspects of object-oriented development, hence the name "Unified Process".

\subsection{The purpose of the RUP Use case Analysis activity is [4]:}

3.1.1 To identify the classes that perform the various flows of events in a use case.

3.1.2 To distribute use case behaviour to these classes, by creating use case realizations.

3.1.3 To identify and assign the responsibilities, attributes and associations to these classes.

To note the need of architectural mechanisms to provide the functionality specified by the use case, and the software system as a whole.

\subsection{Steps of RUP Use-Case Analysis Activity}

Use Case Analysis is composed of several steps in RUP [RUP2003]: 


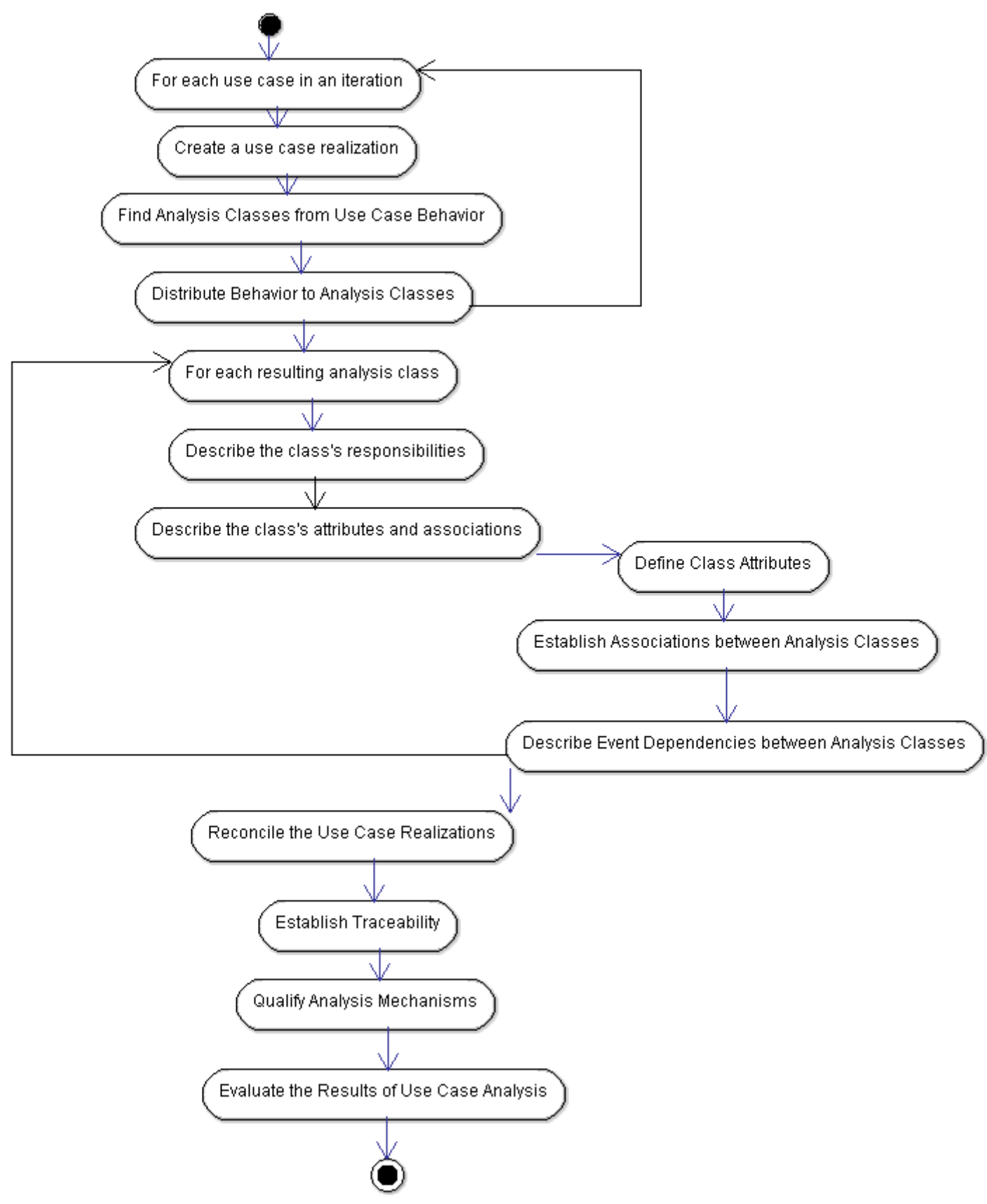

Fig 1: Steps of Use Case Analysis

\subsection{Use Cases to Code}

To get from use cases to code, the following steps are followed:

A Scenario (or use case) is selected on which to begin Use Case Analysis. Then, Use Case Analysis is performed (as shown in the above figure). Following which Use Case Design is performed. Then, Code for the selected use case/scenario is written. If all use cases are coded, the system is complete. Else, another use case (or scenario) is selected for Use Case Analysis[4]

\section{PROPOSED METHODOLOGY} 4.1 Simplified approach to RUP Use-Case Analysis Activity

Simulation of the UC Analysis Activity of RUP is performed. PSP Templates[5] have been used to document scenarios and class, methods, attributes' information.

The following steps have been followed:

4.1.1 Use of XMI Parser for parsing UC Model

4.1.2 Validation of UC Model

4.1.2.1 Each use-case starts with a verb

4.1.2.2 Each use-case is associated with at least one actor and vice-versa 
4.1.3 Use of POS Tagger for extracting nouns and verbs from scenarios

4.1.4 Manually selecting analysis classes based on the nouns, verbs and parsed information from UC model using following guidelines[6]

4.1.4.1 One Boundary Class for each actor-use case pair

4.1.4.2 One Control Class corresponding to each use case

4.1.4.3 Noun filtering technique for Entity classes

4.1.5 Selecting attributes, methods and responsibilities and assigning them to analysis classes

4.1.6 Illustration of Analysis Classes by VOPC Class Diagram

4.1.7 Derivation of UC Metrics, Class Metrics

4.1.8 Establish traceability links

4.1.8.1 Establish traceability links among use case model elements[7]

- Use case to use case section

- Use case to actor

4.1.8.2 Show traceability between UC Model and Analysis Classes Model (Analysis Class realizes use case)

\subsection{Overview of the Tool}

Use-case driven development approach is widely used where use-cases form the basis of analysis, design and testing. The use-case model is subsequently mapped to analysis model, design model and test models. This paper aims to structure the use-case model and identify analysis classes from the usecases and scenarios. The analysis classes can further be mapped to analysis mechanisms. TraceCases performs semiautomated use-case analysis. TraceCases also helps to establish traceability links between the use case model and the analysis model. Various metrics can be developed to quantify the use case and analysis models. Metrics for use-cases and analysis classes have been calculated using TraceCases.

An ATM Case Study is used to illustrate the working of the tool and to validate this approach.

\subsection{RUP in context of PSP}

This work explores RUP in the context of the Personal Software Process (PSP). Templates help us to define a software design completely. Templates in the Personal Software Process (as defined by Humphrey), have many dimensions such as Operational Specification Template, Functional Specification Template, State Specification Template and Logic Specification Template. TraceCases makes use of two templates, viz., Operational Specification Template to store the scenarios and Functional Specification Template to store classes, attributes and methods.
The proposed tool is designed using RUP combined with PSP. It has been studied that PSP Design Templates can directly be mapped to UML models and be used with the Team Software Process[8]. Hence, TraceCases can be extended to be used with the Team Software Process, and hence, be used in the industry.

\section{SIMILAR RESEARCH WORK}

In their work "Automating the Transition from Use Case Model to Class Model'[9], the authors employ use cases to express the functional requirements. The use case specifications are processed using use case language schemas. These schemas reduce the ambiguity, vagueness and complexity of natural English language. A use case processing method is used to analyze the use case diagrams and use case specifications. The analysis artefacts generated include robustness and collaboration diagrams and the class diagram is generated as a design artefact. UCDA CASE tool is developed by the author for generating the diagrams automatically in Rational Rose.

The proposed work also analyzes/processes use case specifications using noun-filtering technique to extract the nouns and verbs. However, it does not use use case language schemas to process the use case specifications. TraceCases also uses XMI to extract the names of actors, use cases and association relationships from the use diagram. The tool draws the VOPC class diagram as an artefact.

In the thesis entitled "Auto-generation of Use case controllers"[10], Pushkar Marathe inputs the requirements model from use case diagram in the form of an XMI file. Then, entity, boundary and controller classes are extracted by parsing this use case diagram. His tool, called Protogen, automatically generates prototypes and hence, code for the controller classes using a hexagonal architecture.

The proposed work is a simulator for RUP. It performs use case analysis and is similar to Protogen in that it extracts entity, boundary and controller classes from a use case diagram input as XMI file. However, no code is generated for these classes. Instead, traceability diagram and metrics are derived from the use case analysis technique.

Other related work in this area includes Rule-based generation of XML Schemas from UML Class Diagrams[11]. In this work, the authors convert the class diagram to XMI and then extract the conceptual data model using XML Schema. This helps in Logical database Design. In Using Alloy to modelcheck visual design notations[12], the authors have made use of a new object-oriented method called Discovery and a tool Alloy to validate five UML diagrams for completeness and consistency. 


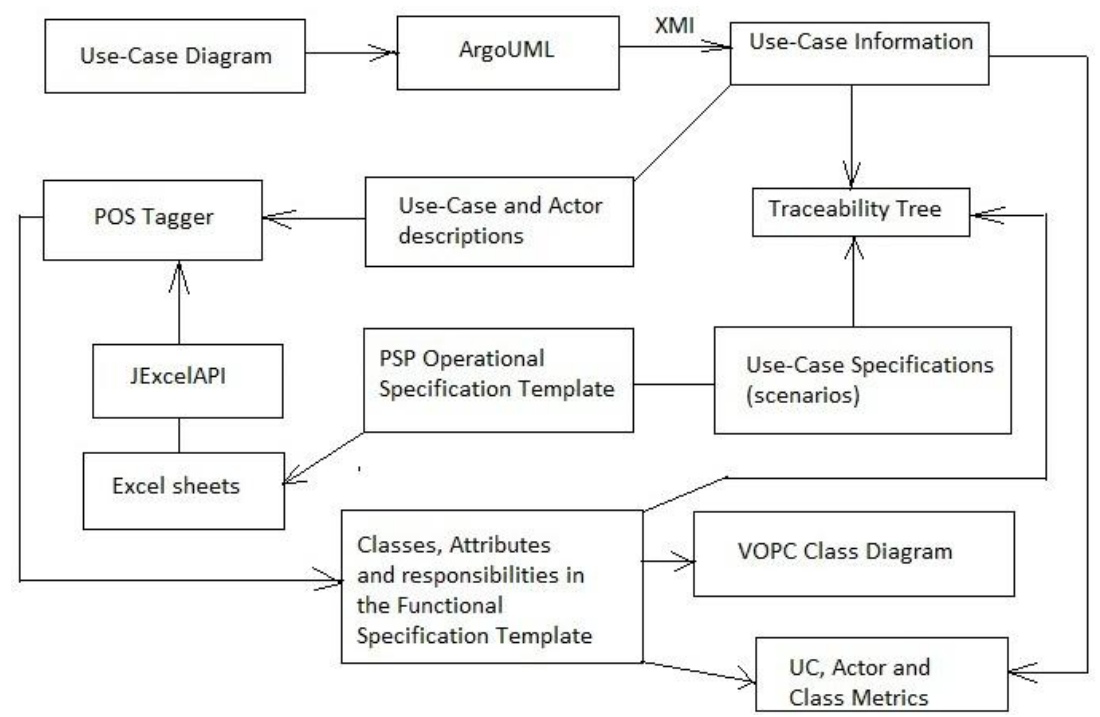

Fig 2: Architecture of TraceCases

\section{RUP CASE STUDY: ATM}

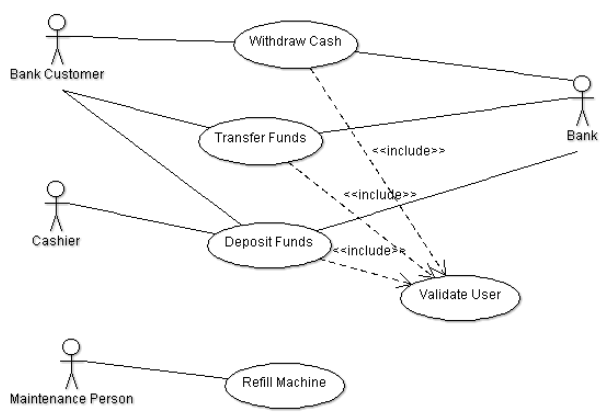

Figure 3: ATM Use case Diagram, taken from [13], redrawn in ArgoUML

\subsection{Scenario for Withdraw Cash Use Case (Modified from [14], stored in Operational Specification Template)}

Table 1: Use case specification of withdraw cash use case

\begin{tabular}{|c|c|c|c|}
\hline $\begin{array}{l}\text { User } \\
\text { Object } \\
\text { ive }\end{array}$ & \multicolumn{2}{|c|}{ Withdraw cash use case } & \\
\hline $\begin{array}{l}\text { Scenar } \\
\text { io } \\
\text { Object } \\
\text { ive }\end{array}$ & \multicolumn{3}{|c|}{$\begin{array}{l}\text { This use case describes how the bank customer uses } \\
\text { the ATM to withdraw money to his/her bank } \\
\text { account }\end{array}$} \\
\hline $\begin{array}{l}\text { Basic } \\
\text { Flow }\end{array}$ & & & \\
\hline $\begin{array}{l}\text { Sourc } \\
\mathrm{e}\end{array}$ & Step & Action & $\begin{array}{l}\text { Comment } \\
\mathrm{s}\end{array}$ \\
\hline $\begin{array}{l}\text { Bank } \\
\text { Custo } \\
\text { mer }\end{array}$ & bf1 & Inserts their bank card & $\begin{array}{l}\text { normal } \\
\text { flow }\end{array}$ \\
\hline $\begin{array}{l}\text { Use } \\
\text { case: } \\
\text { Valida }\end{array}$ & bf 2 & Use case is performed & $\begin{array}{l}\text { normal } \\
\text { flow }\end{array}$ \\
\hline
\end{tabular}

\begin{tabular}{|c|c|c|c|}
\hline \multicolumn{4}{|c|}{ te user } \\
\hline ATM & bf 3 & $\begin{array}{l}\text { The ATM displays the various } \\
\text { list of alternatives that are } \\
\text { available on this unit. }\end{array}$ & $\begin{array}{l}\text { normal } \\
\text { flow }\end{array}$ \\
\hline & bf 3.1 & $\begin{array}{l}\text { In this case, the customer } \\
\text { always selects "Withdraw } \\
\text { cash" }\end{array}$ & $\begin{array}{l}\text { normal } \\
\text { flow }\end{array}$ \\
\hline ATM & bf 4 & Prompts for an account & $\begin{array}{l}\text { normal } \\
\text { flow }\end{array}$ \\
\hline $\begin{array}{l}\text { Bank } \\
\text { Custo } \\
\text { mer }\end{array}$ & bf5 & Selects an account & $\begin{array}{l}\text { normal } \\
\text { flow }\end{array}$ \\
\hline ATM & bf6 & Prompts for an amount & $\begin{array}{l}\text { normal } \\
\text { flow }\end{array}$ \\
\hline $\begin{array}{l}\text { Bank } \\
\text { Custo } \\
\text { mer }\end{array}$ & bf7 & Enters an amount & $\begin{array}{l}\text { normal } \\
\text { flow }\end{array}$ \\
\hline $\begin{array}{l}\text { Syste } \\
\mathrm{m}\end{array}$ & bf8 & $\begin{array}{l}\text { Card ID, PIN, amount and } \\
\text { account is sent to Bank as a } \\
\text { transaction. The Bank } \\
\text { Consortium replies with a } \\
\text { go/no go reply telling if the } \\
\text { transaction is ok }\end{array}$ & $\begin{array}{l}\text { normal } \\
\text { flow }\end{array}$ \\
\hline $\begin{array}{l}\text { Syste } \\
\mathrm{m}\end{array}$ & bf9 & Then money is dispensed & $\begin{array}{l}\text { normal } \\
\text { flow }\end{array}$ \\
\hline $\begin{array}{l}\text { Syste } \\
\mathrm{m}\end{array}$ & bf10 & The Bank Card is returned & $\begin{array}{l}\text { normal } \\
\text { flow }\end{array}$ \\
\hline $\begin{array}{l}\text { Syste } \\
\mathrm{m}\end{array}$ & bf11 & The receipt is printed & $\begin{array}{l}\text { normal } \\
\text { flow }\end{array}$ \\
\hline End & bf12 & The use case ends successfully & $\begin{array}{l}\text { normal } \\
\text { flow }\end{array}$ \\
\hline $\begin{array}{l}\text { Altern } \\
\text { ative } \\
\text { Flows }\end{array}$ & af1 & $\begin{array}{l}\text { Step } 2 \text { does not end } \\
\text { successfully }\end{array}$ & $\begin{array}{l}\text { Invalid } \\
\text { User }\end{array}$ \\
\hline & af1.1 & $\begin{array}{l}\text { The use case ends with a } \\
\text { failure condition }\end{array}$ & $\begin{array}{l}\text { normal } \\
\text { flow }\end{array}$ \\
\hline $\begin{array}{l}\text { Altern } \\
\text { ative } \\
\text { Flows }\end{array}$ & af2 & $\begin{array}{l}\text { the account selected by the } \\
\text { Bank Customer is not } \\
\text { associated with this bank card }\end{array}$ & $\begin{array}{l}\text { Wrong } \\
\text { account }\end{array}$ \\
\hline & af 2.1 & $\begin{array}{l}\text { The ATM shall display the } \\
\text { message "Invalid Account - }\end{array}$ & $\begin{array}{l}\text { normal } \\
\text { flow }\end{array}$ \\
\hline
\end{tabular}




\begin{tabular}{|c|c|c|c|}
\hline & & please try again". & \\
\hline & af 2.2 & The use case resumes at step 4 & $\begin{array}{l}\text { normal } \\
\text { flow }\end{array}$ \\
\hline \multirow[t]{3}{*}{$\begin{array}{l}\text { Altern } \\
\text { ative } \\
\text { Flows }\end{array}$} & af3 & $\begin{array}{l}\text { the Bank Customer enters an } \\
\text { amount that exceeds the } \\
\text { withdrawal limit }\end{array}$ & $\begin{array}{l}\text { Amount } \\
\text { exceeds } \\
\text { withdraw } \\
\text { al limit }\end{array}$ \\
\hline & af3.1 & \multicolumn{2}{|c|}{$\begin{array}{l}\text { the ATM shall display a warning message, } \\
\text { and ask the Bank Customer to reenter the } \\
\text { amount }\end{array}$} \\
\hline & af3.2 & The use case resumes at step 7 & \\
\hline \multirow[t]{3}{*}{$\begin{array}{l}\text { Altern } \\
\text { ative } \\
\text { Flows }\end{array}$} & af4 & $\begin{array}{l}\text { the Bank response indicates the } \\
\text { daily withdrawal limit has been } \\
\text { exceeded (this is determined } \\
\text { by the Bank and depends upon } \\
\text { the specific account) }\end{array}$ & $\begin{array}{l}\text { Amount } \\
\text { exceeds } \\
\text { daily } \\
\text { withdraw } \\
\text { al limit }\end{array}$ \\
\hline & af4.1 & \multicolumn{2}{|c|}{$\begin{array}{l}\text { The ATM shall display a warning message, } \\
\text { and ask the Bank Customer to reenter the } \\
\text { amount }\end{array}$} \\
\hline & af4.2 & The use case resumes at step 7 & \\
\hline \multirow[t]{3}{*}{$\begin{array}{l}\text { Altern } \\
\text { ative } \\
\text { Flows }\end{array}$} & af5 & $\begin{array}{l}\text { the Bank Customer enters an } \\
\text { amount that exceeds the } \\
\text { amount of cash available in the } \\
\text { ATM }\end{array}$ & $\begin{array}{l}\text { Insufficie } \\
\text { nt cash }\end{array}$ \\
\hline & af5.1 & \multicolumn{2}{|c|}{$\begin{array}{l}\text { The ATM will display a warning message, } \\
\text { and ask the Bank Customer to reenter the } \\
\text { amount }\end{array}$} \\
\hline & af5.2 & The use case resumes at step 7 & \\
\hline \multirow[t]{6}{*}{$\begin{array}{l}\text { Altern } \\
\text { ative } \\
\text { Flows }\end{array}$} & af6 & $\begin{array}{l}\text { there is no response from the } \\
\text { Bank within } 3 \text { seconds }\end{array}$ & $\begin{array}{l}\text { No } \\
\text { Response } \\
\text { From } \\
\text { Bank }\end{array}$ \\
\hline & af6.1 & $\begin{array}{l}\text { The ATM will re-try, up to } \\
\text { three times }\end{array}$ & \\
\hline & af6.2 & \multicolumn{2}{|c|}{$\begin{array}{l}\text { If there is still no response from the Bank, } \\
\text { the ATM shall display the message } \\
\text { "Network unavailable - try again later". }\end{array}$} \\
\hline & af6.3 & The ATM shall return the card & \\
\hline & af6.4 & $\begin{array}{l}\text { The ATM shall indicate that it } \\
\text { is "Closed" }\end{array}$ & \\
\hline & af6.5 & $\begin{array}{l}\text { The use case ends with a } \\
\text { failure condition }\end{array}$ & \\
\hline \multirow[t]{4}{*}{$\begin{array}{l}\text { Altern } \\
\text { ative } \\
\text { Flows }\end{array}$} & af7 & $\begin{array}{l}\text { the money is not removed from } \\
\text { the machine within } 15 \text { seconds }\end{array}$ & $\begin{array}{l}\text { Money } \\
\text { Not } \\
\text { Removed }\end{array}$ \\
\hline & af7.1 & \multicolumn{2}{|c|}{$\begin{array}{l}\text { the ATM shall issue a warning sound and } \\
\text { display the message "Please remove cash" }\end{array}$} \\
\hline & af7.2 & \multicolumn{2}{|c|}{$\begin{array}{l}\text { If there is still no response from the Bank } \\
\text { Customer within } 15 \text { seconds the ATM will } \\
\text { re-tract the money and note the failure in } \\
\text { the log }\end{array}$} \\
\hline & af7.3 & $\begin{array}{l}\text { the use case ends with a failure } \\
\text { condition }\end{array}$ & \\
\hline \multirow[t]{4}{*}{$\begin{array}{l}\text { Altern } \\
\text { ative } \\
\text { Flows }\end{array}$} & & $\begin{array}{l}\text { If at point prior to step } 8 \text { in the } \\
\text { basic flow the Bank Customer } \\
\text { selects Quit }\end{array}$ & Quit \\
\hline & & $\begin{array}{l}\text { The ATM shall print a receipt } \\
\text { indicating the transaction was } \\
\text { cancelled }\end{array}$ & \\
\hline & & The ATM shall return the card & \\
\hline & & The use case ends & \\
\hline
\end{tabular}

\subsection{Traceability Identifiers [15] of the use case specification:}

bf2->af1, bf8->af2, bf7->af3, bf8->af4, bf7->af5, bf8->af6, bf9->af7

\subsection{Analysis classes identified from the scenario}

6.3.1 Entity Classes

Customer

ATM

Card

6.3.2 Boundary Classes (one class for each use case-actor pair)

Withdraw cash - Bank Customer pair generates WithdrawCashForm

Withdraw cash - Bank pair generates MonitorWithdrawCashForm

\subsubsection{Control Classes (at least one controller class per use case)}

Withdraw Cash use case generates WithdrawCashController

\subsection{Filtered Candidate Attributes}

Amount

Limit

Transaction

Account

ID

PIN

Cash

\subsection{Filtered Candidate Operations (and responsibilities)}

withdraw

validate

dispense

exceeds

display

issue

remove

select 


\subsection{Assigning attributes and operations to classes - VOPC Class Diagram}
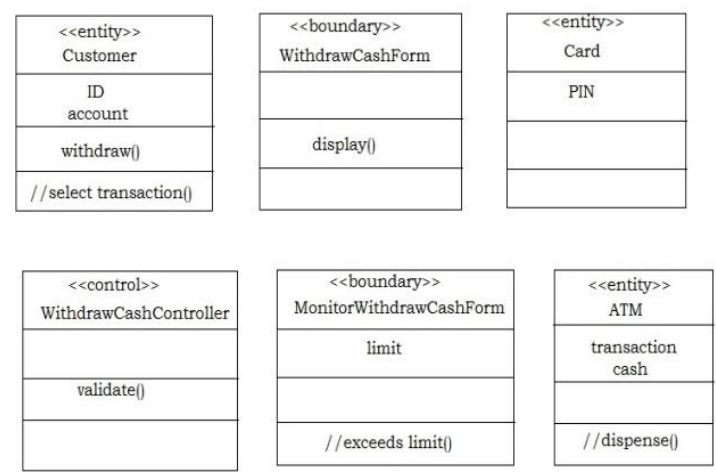

Figure 3: VOPC Class Diagram for Withdraw Cash use case

\subsection{Snapshot of use-case metrics derived - Metrics taken from [16]}

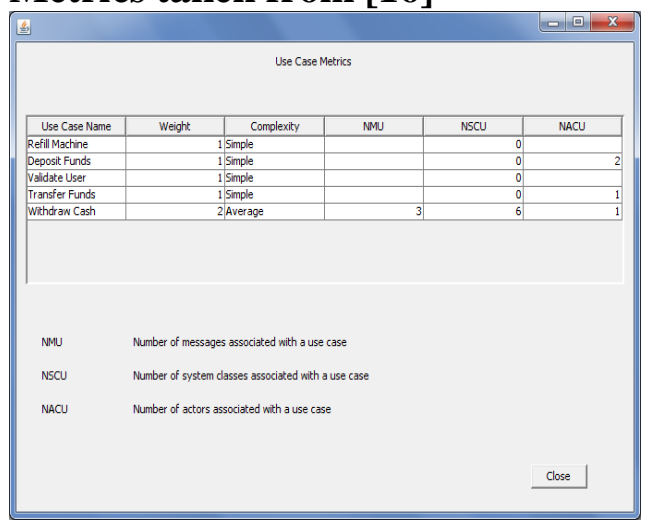

\subsection{Snapshot of class metrics derived - Metrics taken from [16]}

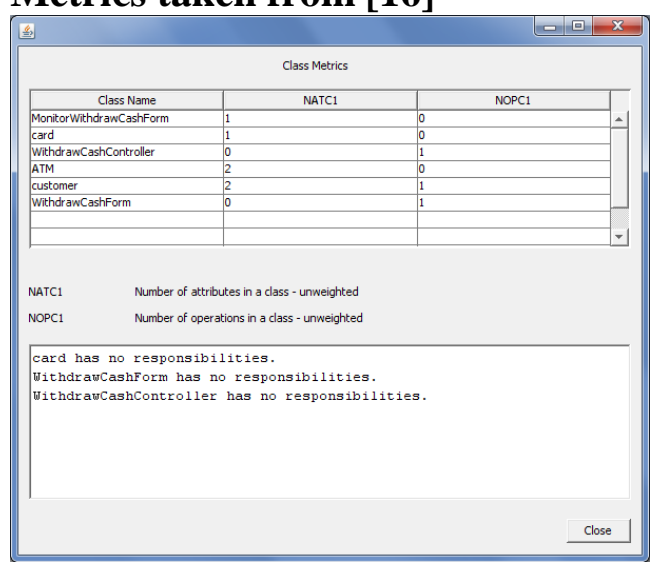

\subsection{Snapshot of Traceability Tree}

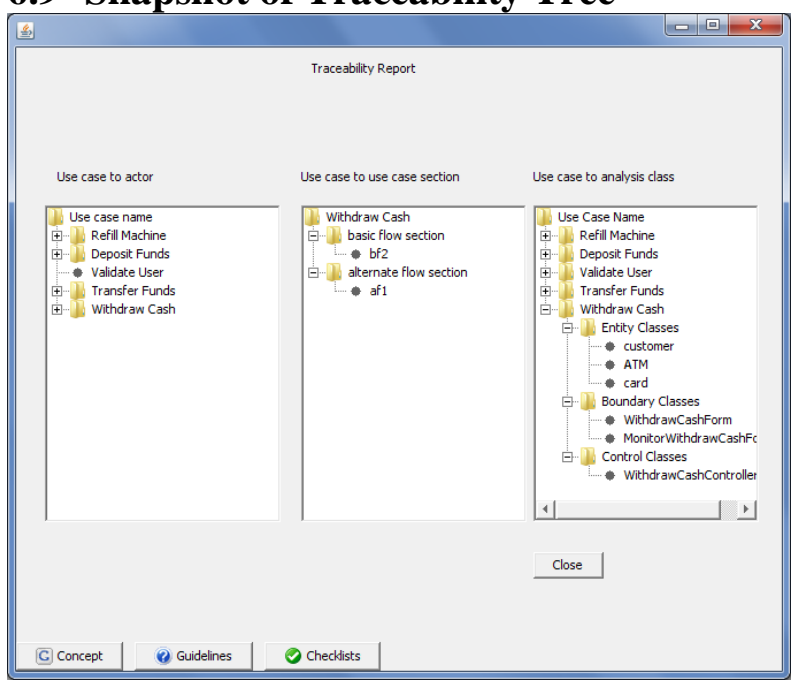

\section{CONCLUSION}

This work is focused more on demonstration of use case analysis rather than documentation of an actual project. Implementing TraceCases has also helped understand about traceability and the issues in its implementation, viz.,

Having just the right degree of granularity is important in a project.

Managing and updating traceability links is a tedious process if done manually.

Experience and training is required for writing and modelling use cases that can be successfully used in analysis and design. Care should be taken to avoid functionally decomposing use cases, over analyzing use case and analysis models, adding the right amount of details in use cases and not mixing analysis and design decisions.[17]

Metrics were also derived based on the use-case model elements and analysis classes. These helped gain an insight into the project considered.

\section{LIMITATIONS OF EXISTING SYSTEM}

This technique relies on scenarios to find nouns and hence, entity classes and attributes. Scenarios are not always available. It is difficult to exhaustively specify scenarios, especially in the beginning of a project. Detailed and accurate scenarios may not be available for all use cases.

For assigning responsibilities to classes based on the scenarios, the internal behaviour of the system needs to be described in use case specifications (scenarios). This internal behaviour is normally not specified in detail while writing scenarios.

\section{FUTURE WORK}

XML Schema may be used to store the use case information as well as the analysis classes' information instead of using a relational database.

The analysis classes can further be refined into design classes or organized into subsystems.

The existing RUP use case analysis process can be enhanced with user experience[18], navigation maps could result from the use cases[19]. 
Architectural mechanisms can be incorporated into TraceCases[20].

Weights can automatically be assigned to use cases based on scenarios by counting the number of transactions.

Responsibilities can be automatically assigned to classes based on the data they contain and the GRASP principles by Larman.

Traceability Identifiers can be used to test exception scenarios and alternative flows through a use case. They can be associated with test cases.

Two PSP Design Templates are being used, viz., Operational Specification Template and Functional Specification Template. Two remaining design templates, viz., Logic Specification Template and State Specification Template can be used in the future.

\section{REFERENCES}

[1] Ahmed F., Campbell P., Jaffar A., Alkobaisi S. Learning \& Personality Types: A Case Study of a Software Design Course published in Journal of Information Technology Education: Volume 9, 2010

[2] O. Coltell, P. Ortiz, A. Fabregat, E. Barrera, G. Xaler, M. Arregui. STRATEGY TO INTRODUCE UML AND RUP IN SOFTWARE ENGINEERING UNDERGRADUATE COURSES in the proceedings of INTED 2009.

[3] Jan Bergandy. "Teaching Software Engineering with Rational Unified Process ${ }^{\circledR}$ (RUP)" in proceedings of the ASEE New England Section 2006 Annual Conference.

[4] Gary Evans. Getting from use cases to code Part 1: Use case Analysis. (http://www106.ibm.com/developerworks/rational/library/5383. html)

[5] PSP Scripts, Forms, Templates, and Standards. Carnegie Mellon University.

[6] Zhao J. Robust Object Oriented Systems Analysis. Dunstan Thomas Consulting.

[7] Spence I., Probasco L. Traceability Strategies for Managing Requirements with Use Case. Rational Software White Paper. TP166, 2000
[8] Webb D.R., Lipkin I., Shraer E.S., Designing in UML with the Team Software Process. CrossTalk: The Journal of Defense Software Engineering, March 2006.

[9] Liu D. Automating Transition from Use Cases to Class Model. A Thesis.

[10] Marathe P. Auto-generation of Use case Controllers. A Thesis. 1-1-2010.

[11] Tobias Krumbein, Thomas Kudrass. Rule-Based Generation of XML Schemas from UML Class Diagrams.

[12] Anthony J. H. Simons, Carlos Alberto Fernandez y Fernandez. Using Alloy to model-check visual design notations.

[13] http://epf.eclipse.org/wikis/abrd/core.tech.common. extend_supp/guidances/examples/uc_model_elabora tion_phase_70035F60.html

[14] http://epf.eclipse.org/wikis/openup/core.tech.comm on.extend_supp/guidances/examples/use_case_spec _CD5DD9B1.html

[15] Roggio R.F., Use Cases and Traceability: a Marriage for Improved Software Quality in Proceedings of the 16th annual NACCQ, Palmerston North, New Zealand, July, 2003.

[16] Kim H. Boldyreff. Developing Software Metrics Applicable to UML Models.

[17] Haumer P. Use Case-Based Software Development. IBM Rational Software.

[18] Westerheim H., Hanssen G.K. Extending the Rational Unified Process with a User Experience Discipline: a Case Study.

[19] Heumann J. User experience storyboards: Building better UIs with RUP, UML, and use cases published in Rational Edge, November 2003.

Kazman R., Kruchten P., Nord R.L., Tomayko J.E. Integrating Software Architecture-Centric Methods into the Rational Unified Process July 2004 TECHNICAL REPORT CMU/SEI-2004-TR-011 ESC-TR-2004-01. 